Provided for non-commercial research and education use. Not for reproduction, distribution or commercial use.

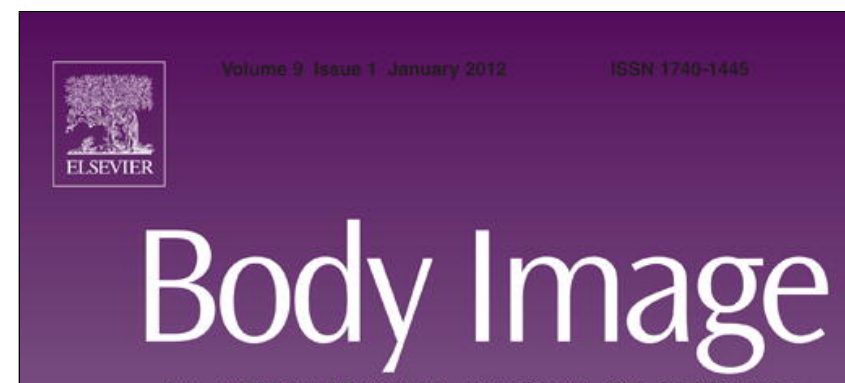

AN INTERNATIONAL JOURNAL OF RESEARCH

Editor-in-Chief

Thomas F. Cash

This article appeared in a journal published by Elsevier. The attached copy is furnished to the author for internal non-commercial research and education use, including for instruction at the authors institution and sharing with colleagues.

Other uses, including reproduction and distribution, or selling or licensing copies, or posting to personal, institutional or third party websites are prohibited.

In most cases authors are permitted to post their version of the article (e.g. in Word or Tex form) to their personal website or institutional repository. Authors requiring further information regarding Elsevier's archiving and manuscript policies are encouraged to visit:

http://www.elsevier.com/copyright 
Review article

\title{
The use of virtual reality in the study, assessment, and treatment of body image in eating disorders and nonclinical samples: A review of the literature
}

\author{
Marta Ferrer-García*, José Gutiérrez-Maldonado \\ Department of Personality, Assessment and Psychological Treatments, Universitat de Barcelona, Barcelona, Spain
}

\section{A R T I C L E I N F O}

\section{Article history:}

Received 21 February 2011

Received in revised form 13 October 2011

Accepted 13 October 2011

\section{Keywords:}

Virtual reality

Body image

Eating disorders

\begin{abstract}
A B S T R A C T
This article reviews research into the use of virtual reality in the study, assessment, and treatment of body image disturbances in eating disorders and nonclinical samples. During the last decade, virtual reality has emerged as a technology that is especially suitable not only for the assessment of body image disturbances but also for its treatment. Indeed, several virtual environment-based software systems have been developed for this purpose. Furthermore, virtual reality seems to be a good alternative to guided imagery and in vivo exposure, and is therefore very useful for studies that require exposure to life-like situations but which are difficult to conduct in the real world. Nevertheless, review highlights the lack of published controlled studies and the presence of methodological drawbacks that should be considered in future studies. This article also discusses the implications of the results obtained and proposes directions for future research.
\end{abstract}

(C) 2011 Elsevier Ltd. All rights reserved.

\section{Contents}

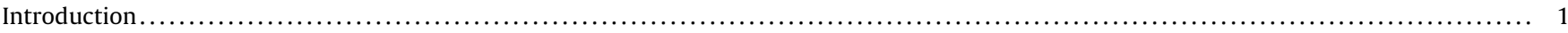

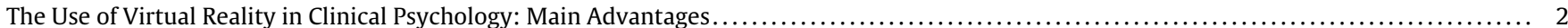

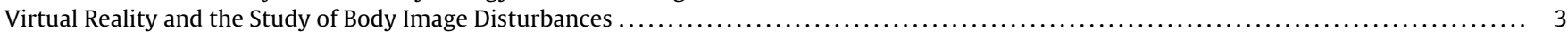

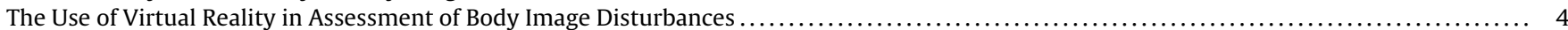

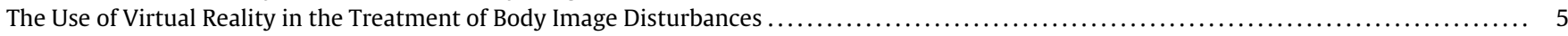

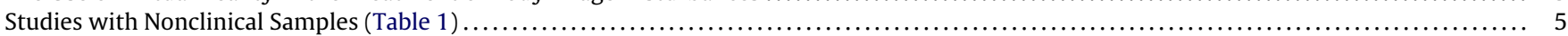

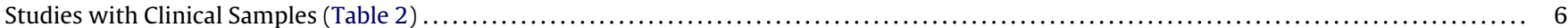

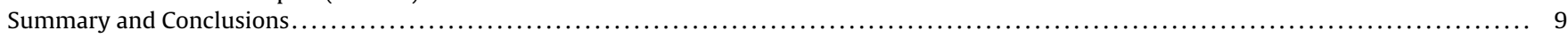

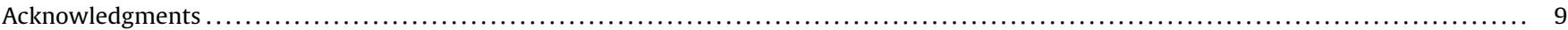

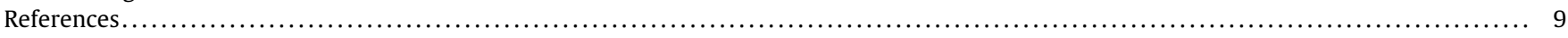

\section{Introduction}

Body image disturbances, especially body image distortion and body image dissatisfaction, have been frequently and strongly associated with the development and maintenance of eating disorders (ED) (Gardner, 2002). Indeed, body image disturbances are a key element in this pathology (Gleaves \& Eberenz, 1993; Striegel-Moore, Franko, Thompson, Barton, Schreiber, \& Daniels, 2004; Vanardo, Williamson, \& Netemeyer, 1995) and form part of the criteria for the diagnosis of both anorexia and bulimia nervosa (APA, 2000). Moreover, body size over-estimation, a wish to

\footnotetext{
* Corresponding author. Tel.: +34 933125116; fax: +34 934021362.

E-mail addresses: martaferrerg@ub.edu (M. Ferrer-García),jgutierrezm@ub.edu (J. Gutiérrez-Maldonado).
}

achieve an extremely thin body, and body dissatisfaction are risk factors for both the development of eating disorders (Cash, 1996; Striegel-Moore \& Cachelin, 2001) and subsequent relapse (Cash \& Deagle, 1997; Crisp \& Kalucy, 1974; Freeman, Beach, Davis, \& Solyom, 1985; Rosen, 1996; Slade \& Russell, 1973). Finally, attitudes toward one's own body image seem to be related to self-esteem, interpersonal confidence, being on a diet, physical activity, grooming behaviours, sexual experiences, and emotional stability (Cash, 1990; Thompson, Heinberg, Altabe, \& Tantleff-Dunn, 1999). Given this, it is not surprising that the study of body image disturbances has become a central subject in the eating disorders literature. However, although it is commonly accepted that body image disturbances play an important role in the development, evolution, and prognosis of ED, they have often been neglected or ascribed only secondary importance in ED treatment programmes (Perpiñá, Botella, Baños, Marco, Alcañiz, \& Quero, 1999). This is probably due, 
at least in part, to the fact that body image is a construct difficult to express and highly resistant to reasoning-based interventions.

Body image is a multidimensional construct reflecting a mental representation of the body's physical appearance and including perceptual, cognitive, and affective aspects, and influences on the person's behaviour (Pruzinsky \& Cash, 2002; Schilder, 1935; Slade, 1988; Williamson, Davis, Bennett, Goreczny, \& Gleaves, 1989). Furthermore, body image is a dynamic representation that the person constructs over time from everyday experiences and in a certain sociocultural context (Bruchon-Schweitzer, 1992). Due this complexity, most research focuses on the study of two disturbances derived from two components of body image (the perceptual and the cognitive-affective components). These two disturbances are the perceptual distortion of body image and body dissatisfaction (Cash \& Brown, 1987; Cash \& Deagle, 1997; Thompson, 1990). Body image distortion entails the inability to perceive the size of the body accurately, and it is usually measured using visual size-estimation tasks. Body satisfaction-dissatisfaction refers to the degree to which a person likes or dislikes the size and shape of his/her body, accepts his or her body, and values it. Body image dissatisfaction is also defined by the discrepancy between perceived body size and ideal body size. It is usually assessed by means of questionnaires or figural or silhouette ratings.

During the last decade the successful implementation of virtual reality (VR) in psychological treatment, especially in the area of phobias, has provided specialists in ED with a technology that by its very nature seems to be particularly suitable for the assessment and treatment of body image disturbances. First, VR allows the development of three-dimensional figures that represent the body of the participant and that can be modified in order to reproduce different components of his or her body image, for example, the perceived body image or the ideal body image. Moreover, the use of immersive systems, such as VR glasses or head mounted displays, allows participants to come to face with their virtual body in the same physical environment and in actual size. Second, VR allows simulating real-live situations related to body image concerns, providing a secure, flexible, and controlled environment where participants are exposed to situations and events that trigger their eating disordered behaviours.

The main purpose of the current paper is to provide a comprehensive and critical review of published literature about the use of virtual reality technology for the study, assessment, and treatment of body image disturbances in ED. The PsycInfo, Medline, and PsycArticles databases were searched by entering the following terms and Boolean operators: virtual reality AND eating disorders AND body image. This initial search produced 27 references. A second search using more complex Boolean operators was then conducted in order to ensure no significant reference was overlooked. The terms and Booleans entered were: (virtual reality OR virtual environment) AND (eating disorders OR anorexia OR bulimia OR EDNOS) AND (body image). This second search produced only two more references. Both searches were conducted for a broad period stretching from 1980, the decade in which the term virtual reality was coined by Lanier (Zimmerman, Lanier, Blanchard, Bryson, \& Harvill, 1986), to 2011.

Among the works compiled, only published research articles were selected. Book chapters and conference presentations were rejected because the studies they referred to already appeared in journal articles. Purely theoretical papers were also excluded. Given that obesity is not an eating disorder and has specific characteristics, studies involving patients with obesity were also excluded. On the other hand, binge eating disorder (BED) was included as it is widely recognized and investigated as an ED. The final selection consisted of 20 studies: 14 focused on treatment and 6 focused in the study of body image disturbances. This review covered studies of both clinical and nonclinical samples.
This review article begins by introducing the use of virtual reality technology in clinical psychology and discussing its main advantages. The article then takes a more detailed look at the published research on the use of VR in the study, assessment, and treatment of body image disturbances in ED and non clinical population. Finally, potential implications of and future research into the use of VR in this area are discussed.

\section{The Use of Virtual Reality in Clinical Psychology: Main Advantages}

At the beginning of the twenty-first century, Norcross and colleagues (Norcross, Hedges, \& Prochaska, 2002) published a study in which, using Delphi methodology, 62 expert psychotherapists were asked to give their views regarding the future of psychotherapy. Of the 38 psychotherapeutic interventions considered, it was predicted that 18 would increase over the next decade. Virtual reality and computer-mediated therapies were among these 18 interventions, being ranked third and fifth, respectively.

Regardless of what one makes of these results, it is a fact that new technologies, especially those arising from the use of computers, are penetrating every area of our lives, from work to leisure. Moreover, in the field of health in general, and especially in the context of mental health, the research conducted on this topic offers promising results. One example of the interest that VR has aroused in the area of psychopathology assessment and treatment is the study by Gregg and Tarrier (2007). These authors reviewed the literature on the use of VR in the field of mental health from 1985 to 2006, identifying more than 50 studies referred to VRbased treatments with at least one patient. Seventeen of these studies compared the effectiveness of VR treatment with in vivo exposure, another treatment, or a no treatment control ( 4 involved patients with fear of flying; 3 involved patients with fear of heights; 3 involved patients with social phobia/public speaking anxiety; 2 involved people with spider phobia; 2 involved patients with agoraphobia; 2 involved patients with body image disturbance; and 1 involved obese patients). Gregg and Tarrier (2007) found that although, in general, VR-based therapy proves to be superior to no treatment, it has not yet been shown to be more effective than most often used therapeutic approaches, such as cognitive behavioural therapy (CBT). The authors suggest that more controlled studies with clinical samples are therefore needed.

Other reviews have shown more optimism about the advantages of VR-based therapy in the context of several psychopathologies, especially anxiety disorders (Côté \& Bouchard, 2008; Cukor, Spitalnick, Difede, Rizzo, \& Rothbaum, 2009; Glantz, Rizzo, \& Graap, 2003; Gorini \& Riva, 2008; Krijn, Emmelkamp, Olafson, \& Biemond, 2004; Maher \& Gold, 2009; Parsons \& Rizzo, 2008; Powers \& Emmelkamp, 2008; Riva, 2005). In general, these reviews suggest that VR-based interventions are at least as effective as those based on CBT. However, it should be noted that VR-based therapies often mix multiple components in their protocols. Thus, VR exposure is usually combined with other cognitive and behavioural techniques and this make difficult separating the specific contribution of this technology to patients' outcomes (Meyerbröker \& Emmelkamp, 2010).

Although the superiority of the RV-based therapies has not been yet proven, this technology has several strengths that raise the interest of clinicians and researchers. In the field of assessment the main advantages of VR are, firstly, it allows a strict control of stimuli while maintaining high ecological validity, since it enables the development of virtual scenarios that are very similar to those of the real world (Gorini, Griez, Petrova, \& Riva, 2010). Furthermore, the use of VR allows researchers to record a large number of responses emitted by the assessed participant (e.g., eye movements, facial 
gestures), as well as providing feedback from the application, which is a useful tool in those studies where simulation requires complex sensory effects. Finally, it is highly flexible and can be adapted to the specific needs of each user.

As regards the scope of treatment, Botella and colleagues (Botella, Baños, García-Palacios, Quero, Guillén, \& José-Marco, 2007; Botella, Baños, Perpiñá, \& Ballester, 1998; Botella, Quero, Baños, Perpiñá, García-Palacios, \& Riva, 2004; Glantz et al., 2003) specify several advantages that have been summarized by Gutiérrez-Maldonado (2009). Providing a safe and flexible environment in which users may face feared situations at their own pace, offering a strict control of the situational parameters, allowing selftraining, and enabling users to go beyond reality, are some of the main advantages of this technology. VR also has specific benefits compared to traditional methods of exposure (in vivo exposure and imagery exposure). Compared with in vivo exposure VR provides a greater degree of confidentiality, as treatment is done in the office. It also avoids travel to feared contexts, thus saving time. Furthermore, by enabling the control of stimuli, and avoiding unforeseen events, it helps to grade the exposure to the patient's own pace, thus reducing any resistance to accept exposure to the feared situation. Finally, it enables therapists to conduct treatments in which it is impossible or very difficult to apply in vivo exposure, for example, flying phobia. Compared with imagery exposure VR is much more immersive, because it stimulates several sensory modalities (auditory, visual, and vestibular). This makes it useful for people who have trouble imagining scenes and facilitates the emotional involvement of participants (Riva, 2003). In addition, the therapist can know at each moment what the patient is seeing and, therefore, can more easily identify which stimuli are causing a particular emotional response.

The use of VR also has certain drawbacks. Some users report experiencing simulator sickness during VR exposure. Simulator sickness encompasses a wide core of potential symptoms, including nausea, disorientation, headache, sweating, dizziness, general fatigue, eye strain, and blurred vision (Casali, 1986; Ebenholtz, 1992). Likewise, the use of VR involves the acquisition and management of special devices that can be expensive and require some training. Nevertheless, the widespread use of virtual reality in everyday life, especially in the field of entertainment, entails a progressive reduction in the cost of this technology, as well as a better understanding of their management by the general population.

\section{Virtual Reality and the Study of Body Image Disturbances}

VR technology has been used to increase knowledge about the body image concept. The team of Gutiérrez-Maldonado at the University of Barcelona (Spain) studied the intra-individual variability of body image in women with anorexia and bulimia nervosa.

Previous research suggested that body image may be more a state than a trait (Slade \& Brodie, 1994; Smeets, 1997; Thompson, 1996), and may change according to situational or emotional variables (Cash, Fleming, Alindogan, Steadman, \& Whitehead, 2002). Thus, several studies analysed the influence exerted on body image by eating low and high calorie food (Crisp \& Kalucy, 1974; McKenzie, Williamson, \& Cubic, 1993; Wardle \& Foley, 1989), being exposed to low and high calorie food (Carter \& Bulik, 1994), being exposed to photographs of low and high calorie food (Heilbrun \& Flodin, 1989; Laberg, Wilson, Eldredge, \& Nordby, 1991), and being exposed to situations that involve the scrutiny of others using guided imagery (Haimovitz, Lansky, \& O'Reilly, 1993). These studies suggested that body image, or some of its components, could indeed be understood as a state rather than as a trait.

In fact, Myers and Biocca (1992) referred to the instability of body image almost 20 years ago, and more recently other authors
(Etu \& Gray, 2010; Lattimore \& Hutchinson, 2010; Rudiger, Cash, Roehrig, \& Thompson, 2007) stressed that trait and state components coexist in this construct. The trait perspective pertains to intra-individual stability of body image. By contrast, the state perspective focuses on the existence of intra-personal variability.

In order to delve further into this issue with VR methodology, Gutiérrez-Madonado and colleagues conducted several studies. One hundred eight female undergraduate students and 85 ED patients were exposed to six VR environments presented in random order (i.e., a neutral room, a kitchen with low-calorie food, a kitchen with high-calorie food, a restaurant with low-calorie food, a restaurant with high-calorie, and a swimming pool). These virtual environments were developed using the information obtained from a survey of 68 ED patients, who were asked about the situations and specific aspects of these situations that caused them body image discomfort. Participants were randomly exposed to the virtual environments. In the interval between the presentation of each environment, the State-Trait Anxiety Inventory (Spielberger, Gorsuch, \& Lushene, 1970), the Barcelona Depression Questionnaire (Pérez, Gutiérrez, \& Ferrer, 2004) and the Body Image Assessment Software (Ferrer-García \& Gutiérrez-Maldonado, 2008) were administrated. The main reasons for using VR in this research was that, unlike the conventional methods such as those used in the previously mentioned studies (e.g., in vivo exposure to the situation, exposure to photographs, exposure via guided imagination, etc.), VR exposes subjects to interactive three-dimensional environments that simulate real situations but allowing a strict control over the parameters of the situation. Moreover, VR is able to include both distal (e.g., eating in a restaurant) and proximal cues (e.g., pizza). Furthermore, ED patients are much more reluctant to engage in in vivo exposure to these situations than to VR exposure to them.

Two groups of data arose from this research. The first set of data provides information that supports the ability of VR environments for eliciting emotional responses, more specifically anxiety and depressed mood in ED patients and controls. This is a necessary step before using these environments to study their influence on the body image of participants. Conclusions drawn from this first set of data and review of the literature are presented below. The second group of data refers specifically to the study of body image disturbances from the state perspective using VR.

Regarding the first set of data, Ferrer-García, GutiérrezMaldonado, Caqueo-Urízar, and Moreno (2009) found that, compared with controls, patients with ED showed significantly higher levels of anxiety and a more depressed mood after visiting all the virtual environments. More specifically, ED patients showed significant higher levels of anxiety and depressed mood after eating (especially high-calorie food) as well as after visiting the swimming pool, than after visiting the neutral room. The significance of these results is that when faced with virtual reality situations both patients with ED and controls seems to react in a similar way to how they would in real life. These results agree with previous research conducted by the same team. Gutiérrez-Maldonado and colleagues (Gutiérrez-Maldonado, Ferrer-García, Caqueo-Urízar, \& Letosa-Porta, 2006) exposed 30 female ED patients to six virtual environments (the neutral situation, the kitchen with high-calorie food, the kitchen with low-calorie food, the restaurant with high-calorie food, the restaurant with low-calorie food, and the swimming pool). The researchers found that, compared with the neutral room, ED patients experienced significant higher levels of anxiety and depressed mood in those environments where they had to eat high-calorie food and in the swimming pool.

Recently, Gorini et al. (2010) tested the emotional reaction of 10 AN patients, $10 \mathrm{BN}$ patients, and 10 healthy control subjects to real food, VR food, and photographs of food. Authors found that real food and VR food produced comparable emotional reactions in ED patients and that this reaction was stronger than the one produced 
by photographs of food. The results obtained with both in vivo and VR exposure appear to be similar, and this is an extremely important finding since it indicates that these environments could be used for both evaluative and therapeutic aims.

Other studies have assessed the ability of VR to elicit emotional, cognitive, and behavioural responses in ED patients similar to those observed in real life. Perpiñá, Botella, Quero, Marco, and Baños (2001) conducted a pilot study with a small sample of ED patients (five with BN and four with BED) with the aim of analysing the use of virtual environments to assess and treat binge eating episodes. The virtual environment presented to participants was the kitchen area, where forbidden (high-calorie) and permitted (low-calorie) food could be found. Participants were then asked to eat the forbidden food, usually a pizza. The results showed that the virtual environment was able to provoke the undesirable features present in binge-eating episodes. First, once a forbidden food had been eaten, patients reported anxiety, impulse to over-eat, and guilt feelings (from moderate to extreme). Furthermore, all the patients said they experienced a strong sense of reality in the virtual environment. Secondly, when augmented reality was added in a second VR exposure session (patients smelled a actual hot pastry for the duration of the virtual eating process), scores on all measures increased. Therefore, augmented reality seems useful for the purpose of helping participants to immerse themselves in the virtual situation and experience it more intensely.

Finally, it is interesting to note that VR exposure also produces emotional responses in a subclinical population. Aimé and colleagues (Aimé, Cotton, \& Bouchard, 2009) exposed 27 women to three virtual environments-the office (neutral environment), the restaurant (with high- and low-calorie food), and the swimming pool. Anxiety was measured before, during, and after immersions. Weight, shape, and food concerns, drive for thinness, and body dissatisfaction were also measured after immersions. The authors found that participants who showed elevated but subclinical concerns with their weight and shape $(n=10)$ showed significantly higher level of anxiety and weight concerns after visiting the restaurant and the swimming pool than visiting the neutral situation. On the other hand, participants who did not show concerns with their weight and shape $(n=17)$ did not show anxiety or concerns after visiting the restaurant and the swimming pool.

Review of the first set of data obtained from the research of Gutiérrez-Maldonado and colleagues shows that VR environments are useful for producing similar responses to those observed in real world. Therefore, these environments can be useful for studying intra-individual variability of body image disturbances. The second group of data drawn from the study of Gutiérrez-Maldonado provides evidence to this statement.

The second group of data refers to the study of body image from the state perspective using VR. Gutiérrez-Maldonado and colleagues (Ferrer-García \& Gutiérrez-Maldonado, 2010; GutiérrezMaldonado, Ferrer-García, Caqueo-Urízar, \& Moreno, 2010) studied whether perceptual distortions in body image and body dissatisfaction changed depending on the situation. Only four virtual environments were used (the kitchen with low-calorie food, the kitchen with high-calorie food, the restaurant with low-calorie food, and the restaurant with high-calorie food), as the authors specifically wanted to determine the influences of the kind of food (high or low calorie) and of the presence of people on body image disturbances. The results showed that patients with ED displayed a significantly higher over-estimation of body size (body image distortion) and significantly greater body dissatisfaction after eating high-calorie food than after eating low-calorie food. In contrast, participants without ED showed similar percentages of over-estimation and body dissatisfaction in both situations. The presence or absence of people in the virtual environments had no significant effect on body image distortion. The authors conclude that body image distortion and body image dissatisfaction change depending on the situation to which participants are exposed. These results indicate that body image can indeed be understood as a state rather than solely as a trait, and that these states are modified when participants are exposed to situations which are emotionally relevant for them. Moreover, this study shows that food type appears to be an emotionally significant stimulus for patients with $\mathrm{ED}$, one which is capable of producing changes in their body image, whereas the mere presence or absence of people has no such effect. Thus, body image distortion and body image dissatisfaction can be influenced by situational factors, and VR exposure is a useful technology for their study.

The evidence that body image disturbances act partially as a state is important and has therapeutic implications. Changing the body image experience of ED patients is one of the most difficult therapeutic goals to achieve (Rorty, Yager, \& Rossoto, 1993), and yet traditional treatment programmes usually devote fewer sessions to this component than to disturbed eating behaviour (Rosen, 1997; Rosen \& Ramírez, 1998). However, by using different virtual scenarios, which represent a range of stressful real-life situations for ED patients, the inclusion of body image assessment could provide clear and therapist-independent information about the subjective view that patients have of their bodies, as their perception and judgments change depending on the situation they have been exposed to. This would offer patients with ED hard evidence that their body image is just a mental representation which may differ greatly from objective reality.

\section{The Use of Virtual Reality in Assessment of Body Image Disturbances}

There are two main research groups who have used VR technology in the assessment and, especially, the treatment of body image disturbances in ED: one is the group of Riva in Milan (Italy) and the other the group of Perpiñá in Castellón and Valencia (Spain). Both groups use VR to improve cognitive-behavioural therapy, although each highlights different benefits of using this technology or justifies its use in different ways.

The pioneering studies on the application of VR for the assessment and treatment of body image disturbances were conducted by Riva and his team (Riva, Melis, \& Bolzoni, 1997) in the context of the European VREPAR Project (Virtual Reality Environments for the Psycho-neuro-physiological Assessment and Rehabilitation Project). The main purposes of this project were, firstly, to study certain mental disorders and, secondly, to develop new therapeutic techniques for their treatment and rehabilitation. As a part of this broad project, the Virtual Body Project was also developed with the aim of creating virtual environments for the study, assessment, and treatment of body image disturbances in ED.

In this context, Riva and colleagues developed a software package for the assessment of body image disturbances, known as the BIVRS (Body Image Virtual Reality Scale; Riva, 1998a; Riva \& Melis, 1997). The BIVRS is a non-immersive, 3D graphical interface through which the participant can choose between nine figures, male and female, ranging from underweight to overweight. Participants must choose those figures that best fit their self-perceived and their desired body size. Discrepancy between the two measures is an indicator of body image dissatisfaction. In fact, the BIVRS improves upon traditional assessment methods based on silhouettes by adding the third dimension to the figures presented to the user; consequently, the figures are more realistic and this makes it easier for participants to identify with them.

Perpiñá and colleagues in Spain (Perpiñá, Botella, \& Baños, 2000) developed another application for the assessment and treatment of body image disturbances in ED. The assessment software 
consists of a 3D human figure whose body parts size can be modified. A slider bar for each body part appears on the computer screen besides the 3D human figure. Participants can enlarge the size of each body part by moving the slider to the right end of the bar or can make it smaller by moving the slider to the left end of the bar. The main advantage of this application is that, as it is immersive, the user can manipulate the figure while both are in the same virtual environment, which implies that the figure presented to the user has a similar size. This method also assesses several dimensions or indices of body image (e.g., the perceived body, the desired body, the healthy body, etc.) and body weight (actual weight, subjective weight, healthy weight, and desired weight), and all in different contexts (e.g., before and after eating in the kitchen).

The BIVRS and the software developed by Perpiñá have been mainly used in the treatment context. Riva uses it in several studies for measuring changes in body image disturbances after treatment. Perpiñá uses it as a part of her VR-based treatment, both for assessment purposes and as a way to confront the patients with their disturbed body image. However, no psychometric studies about these assessment tools have been published.

\section{The Use of Virtual Reality in the Treatment of Body Image Disturbances}

Riva and colleagues (Riva \& Melis, 1997; Riva et al., 1997) were also pioneering in the development of a VR application for the treatment of body image disturbances: the VEBIM (Virtual Environment for Body Image Modification). The VEBIM consists of five virtual reality environments or zones grouped into two parts. The first part (Zone 1: training room and balance; and Zone 2: kitchen and office) was developed, firstly, so that users could acquire the minimum skills necessary to navigate and interact with the environment, and secondly, to identify which stimuli are capable of eliciting disturbed eating behaviours. Three additional virtual areas (Zone 3: pictures of models; Zone 4: the mirror room; and Zone 5: the room of doors) were developed to modify the user's body image. During exposure to different environments the Socratic Method is used to help participants challenge distorted thoughts about their body weight and shape, and to develop a more realistic perception of their own body (Riva, Bacchetta, Baruffi, Rinaldi, \& Molinari, 1998). In addition, combining the BIVRS with the VEBIM can provide information about changes in the user's body image during the exposure experience.

According to its developers, the main advantage of the VEBIM is that it is able to integrate the cognitive-behavioural and the visualmotor approaches to body image disturbance treatment in ED. In general, the cognitive-behavioural approach focuses on modifying patients' thoughts and feelings of dissatisfaction with different parts of their body while the visual-motor approach focuses on increasing body awareness using video-recording of particular movements and postures (Riva, Bacchetta, Baruffi, Defrance, et al., 1999). Riva starts from the premise that body image is a cognitive bias and, as such, it is barely accessible to consciousness. This fact hinders body image change, as users believe that biased information is valid (Riva, 2003). However, due to the intrinsic features of the technology, the virtual experience gives users access to this unconscious information related to body schemata. Common distortions and desynchronisations produced in VR systems can alter people's lived experience. Discrepancies between the signals arriving from the user's propioceptive system and the external signals from the virtual environment alter body perceptions. This effect can be used for therapeutic purposes, as they involve a greater awareness of the associated sensorimotor and perceptual processes. When a particular event or stimulus is discordant with body schematic information, such as occurs during the virtual experience, this information becomes conscious (Baars, 1988). Furthermore, VR experience may enhance cognitive-behavioural techniques: "Using VR the therapist can actually demonstrate that what looks like a perception does not really exist. This gets across the idea that a person can have a false perception. Once this has been understood, individual maladaptative assumptions can then be challenged more easily" (Riva, Bacchetta, Baruffi, Defrance, et al., 1999, p. 78).

Perpiñá and colleagues (Perpiñá et al., 2000) also developed six virtual reality environments for treating body image disturbances: the training room, the kitchen and food area, the poster room, the room with two mirrors, and the room with six mirrors. To use the program, the clinician must enter data for each patient into the corresponding database (actual weight, healthy weight, height, actual body shape, face and profile, healthy body shape). Additionally, the professional introduces the weight of the patient before starting the session. The answers given by the patient during each session are stored in a database.

Perpiñá and colleagues (Perpiñá, Botella, \& Baños, 2003) suggest that the main reason why VR is a useful technology in the assessment and treatment of body image disturbances is its ability to capture something as subjective as body image, a mental representation. The VR software developed by Perpiñá and colleagues included 3D human figures that participants can modify in order to represent several aspects of their body image, such as their ideal body image and their perceived body image. According to the authors, this allows participants to model, reflect, and embody their body mental representations, while at the same time informing the therapist. It is also a useful tool for bringing patients face to face with their body image disturbances. Furthermore, authors' clinical experience with VR-based therapy showed them that this technology is perceived by patients as an impartial judge, and hence the information provided to users about their appearance is not received with suspicion, enabling it to be accepted with less resistance. Consequently, patients find it easier to consider the possibility that they may be distorting their body image, either at a perceptual, evaluative, emotional, or contextual level, because it is the virtual system and not the therapist who shows them this. Finally, as we have seen from the benefits of VR in the treatment of psychological disorders, this technology allows users to face their fears in a protected environment before being exposed to the real situation. This increases their motivation to engage in treatment.

Tables 1 and 2 summarize the studies reviewed about the effectiveness of including the virtual reality technology in the treatment of body image disturbances. Note that the results of publications that refer to the same research appear together despite addressing different aspects of the study in order to facilitate interpretation of the tables.

\section{Studies with Nonclinical Samples (Table 1)}

Studies about the effectiveness of VR-based treatment on body image disturbances started at the end of the 1990s. Riva and colleagues conducted three preliminary studies with non clinical population to assess the VEBIM (Riva, 1998b, 1998c; Riva \& Melis, 1997; Riva et al., 1997). In these studies, exposure to VEBIM during no more than 10 min produced changes on body image dissatisfaction (the discrepancy between the perceived and the ideal body size). Specifically, body dissatisfaction levels were significantly lower after leaving the VEBIM than before entering (see Table 1). Riva (1998c) also studied whether exposure to VEBIM produced psychophysiological changes in a sample of 47 males and 24 females. Blood pressure and heart rate were assessed. No differences were found between measures obtained before and after the virtual experience. Finally, it is interesting to note that, in only 
Table 1

Studies about the effectiveness of including VR in the treatment of body image disturbances in nonclinical samples.

\begin{tabular}{|c|c|c|c|c|c|c|}
\hline Type & Author(s), year & Condition(s) & $N($ total $)$ & Sessions & $\begin{array}{l}\text { Dependent } \\
\text { variables }\end{array}$ & $\begin{array}{l}\text { Outcome } \\
\text { (effectiveness) }\end{array}$ \\
\hline \multirow[t]{3}{*}{$\begin{array}{l}\text { Uncontrolled } \\
\text { studies }\end{array}$} & Riva et al. (1997) & 1 VEBIM & $\begin{array}{l}49 \text { males } \\
31 \text { females }\end{array}$ & $\begin{array}{l}8-10 \text { min exposure } \\
\text { to VEBIM }\end{array}$ & FRS, CDRS & $\begin{array}{l}\text { Decreased body } \\
\text { dissatisfaction (lower } \\
\text { ideal body scores). } \\
\text { No simulator sickness }\end{array}$ \\
\hline & $\begin{array}{l}\text { Riva and Melis (1997) } \\
\text { Riva (1998c) }\end{array}$ & 1 VEBIM & $\begin{array}{l}47 \text { males } \\
24 \text { females }\end{array}$ & $\begin{array}{l}8-10 \text { min exposure } \\
\text { to VEBIM }\end{array}$ & $\begin{array}{l}\text { Blood pressure, } \\
\text { heart rate, FRS, } \\
\text { CDRS, and BCRS }\end{array}$ & $\begin{array}{l}\text { No significant } \\
\text { differences in blood } \\
\text { pressure and heart rate } \\
\text { were found before and } \\
\text { after the VR experience } \\
\text { Two participants } \\
\text { experienced simulator } \\
\text { sickness } \\
\text { Significant reduction of } \\
\text { body dissatisfaction }\end{array}$ \\
\hline & Riva (1998b) & 1 VEBIM & 24 females & 10 min exposure & FRS, CDRS & $\begin{array}{l}\text { Significant reduction of } \\
\text { BI dissatisfaction } \\
\text { No simulator sickness }\end{array}$ \\
\hline Controlled studies & Riva (1998d) & $\begin{array}{l}2 \text { (between } \\
\text { subject): } \\
\text { VEBIM and WL }\end{array}$ & $\begin{array}{l}48 \text { females } \\
\text { VEBIM }(n=24) \\
\text { WL }(n=24)\end{array}$ & $\begin{array}{l}\text { Experimental } \\
\text { group: } 8-10 \text { min of } \\
\text { exposure to VEBIM } \\
\text { Control group: } \\
10 \text { min between } \\
\text { pre and post-test }\end{array}$ & FRS, CDRS, BCRS & $\begin{array}{l}\text { Reduction of BI } \\
\text { dissatisfaction after } \\
\text { VEBIM } \\
\text { No changes in controls. } \\
\text { No simulator sickness }\end{array}$ \\
\hline
\end{tabular}

Note: See Table 2 for explanation of abbreviations.

one of these studies (Riva, 1998c), two participants experienced simulator sickness.

A controlled study was conducted subsequently in order to test the results previously obtained (Riva, 1998d). Forty-eight women were randomly assigned to two groups: the experimental group, in which the VEBIM was administered, and the control group, without treatment. The experimental group showed a significant reduction in body image dissatisfaction after visiting the VEBIM compared with pretest measures. On the other hand, the control group did not show any significant change across the two measures. These results supported the usefulness of the VEBIM in reducing body dissatisfaction among participants without any psychological disorder, thus paving the way for its application in clinical settings. Furthermore, only two cases of simulator sickness were found, which reinforced the possibility of using this technology for therapeutic purposes.

\section{Studies with Clinical Samples (Table 2)}

Given the encouraging results of preliminary studies, Riva and colleagues (Riva et al., 1998, 1999b) administered these virtual environments to a 22-year-old woman with AN (purging type). The treatment used was experiential cognitive therapy (ECT), which uses an enhanced version of the VEBIM in combination with cognitive-behavioural treatment and psychoeducation about nutrition and proper handling of medication. After eight treatment sessions the participant increased awareness of her own body. Altering her body representation allowed this patient to reduce significantly her level of body dissatisfaction. There was also a reduction in the avoidance behaviours and grooming habits associated with a negative body image. Perpiñá and colleagues (Perpiñá, Baños, Botella, \& Marco, 2001) found an improvement in the ED patient's symptomatology at 1-year follow-up in another case study. Salorio and colleagues (Salorio et al., 2004) published another case study in which they applied a 10-session treatment programme based on the treatment developed by Perpiñá and her team (Perpiñá et al., 2000) to an AN patient. The authors reported (on the Eating Disorders Inventory) decreased body dissatisfaction, better interoceptive awareness, less perfectionism, and no tendency toward asceticism in the treated participant. Furthermore, at 1 -year follow-up the patient showed less drive for thinness, more body satisfaction, and less interpersonal distrust, while perfectionism, asceticism, and social insecurity were all absent.

Perpiñá and colleagues (Perpiñá et al., 1999) conducted the first controlled study with a clinical sample (patients with AN or BN) to test the efficacy of virtual reality in the treatment of body image disturbances in ED. With this objective the researchers compared two treatment conditions: the VR condition (cognitive-behavioural treatment + VR) and a standard treatment for body image disturbances (cognitive-behavioural treatment + relaxation). All patients who completed treatment $(n=13)$ showed a significant improvement, but those who were treated with the VR component showed a significantly greater improvement in general psychopathology, ED-related psychopathology, and specific body image variables (higher level of satisfaction with their body in social situations, fewer thoughts and negative attitudes toward the body, less anxious about their weight, and less fearful of achieving a healthy weight). It should also be noted that the dropout rate was lower in the VR group, indicating an increased motivation and adherence to treatment. A second study with a sample of $12 \mathrm{ED}$ patients ( 7 with AN and 5 with BN) showed that the improvement achieved after completing the treatment was not only maintained after 12 months but actually increased (Perpiñá, Marco, Botella, \& Baños, 2004).

Riva and colleagues (Riva, Bacchetta, Baruffi, \& Molinari, 2002) conducted another controlled study with a group of 20 patients with BED. Authors compared two treatments: the VREDIM (Virtual Reality for Eating Disorders Image Modification; $n=10$ ), which is a revised version of the VEBIM, and a psycho-nutritional intervention $(n=10)$ based on cognitive-behavioural approach. Participants in both conditions also followed a low-calorie diet and received physical training during treatments. Although there were no differences in the reduction of binge eating behaviour between treatments, patients in VREDIM group showed less body dissatisfaction. Moreover, VREDIM was more effective than the psycho-nutritional intervention in improving self-efficacy, motivation for change and general psychological state. Authors did not report follow-up data in this study.

The same research group (Riva, Bacchetta, Cesa, Conti, \& Molinari, 2003) published an interesting study where three different treatments and wait-list controls were compared. Thirty-six women with BED participated in the study. Patients were randomly 
M. Ferrer-García, J. Gutiérrez-Maldonado / Body Image 9 (2012) 1-11

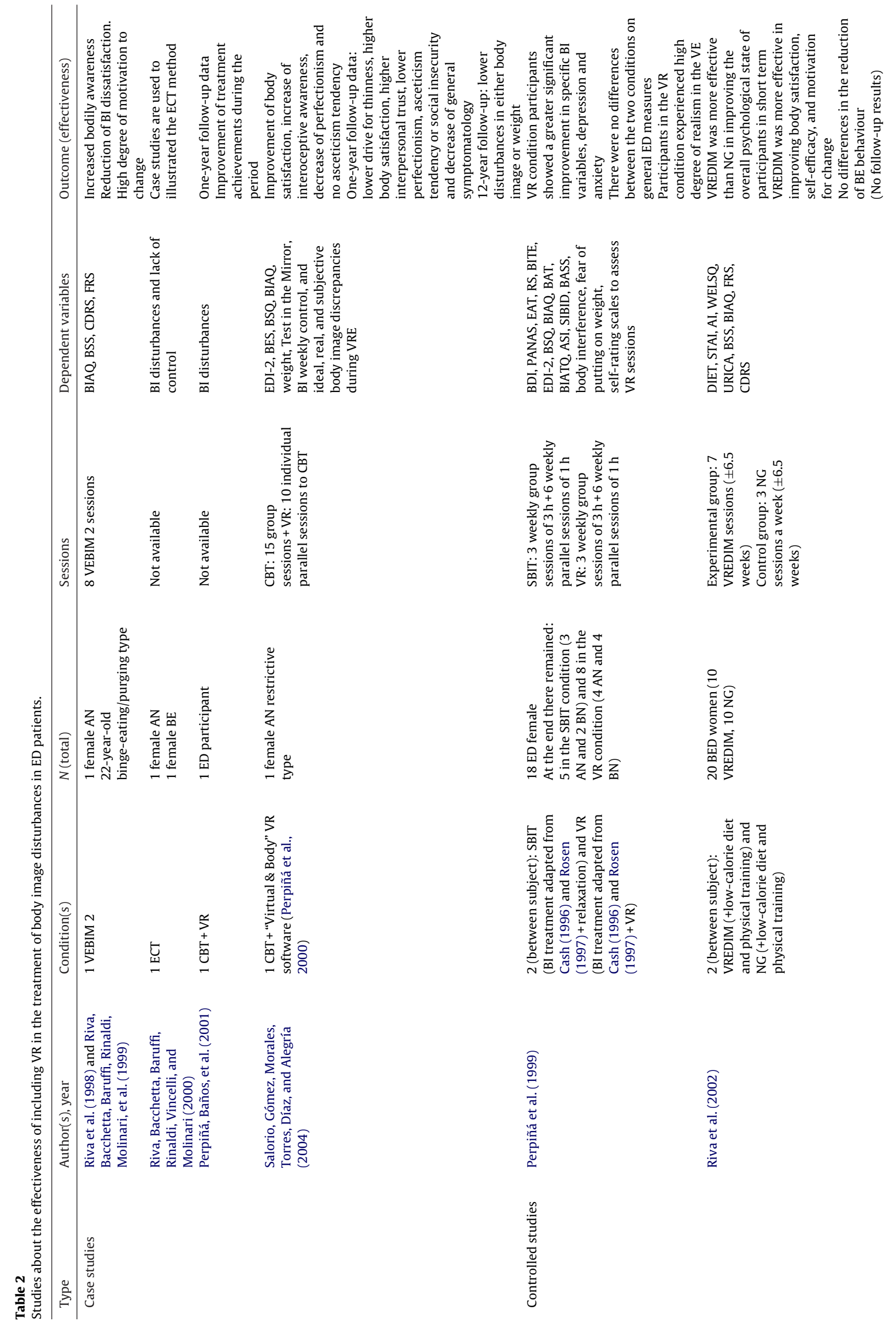




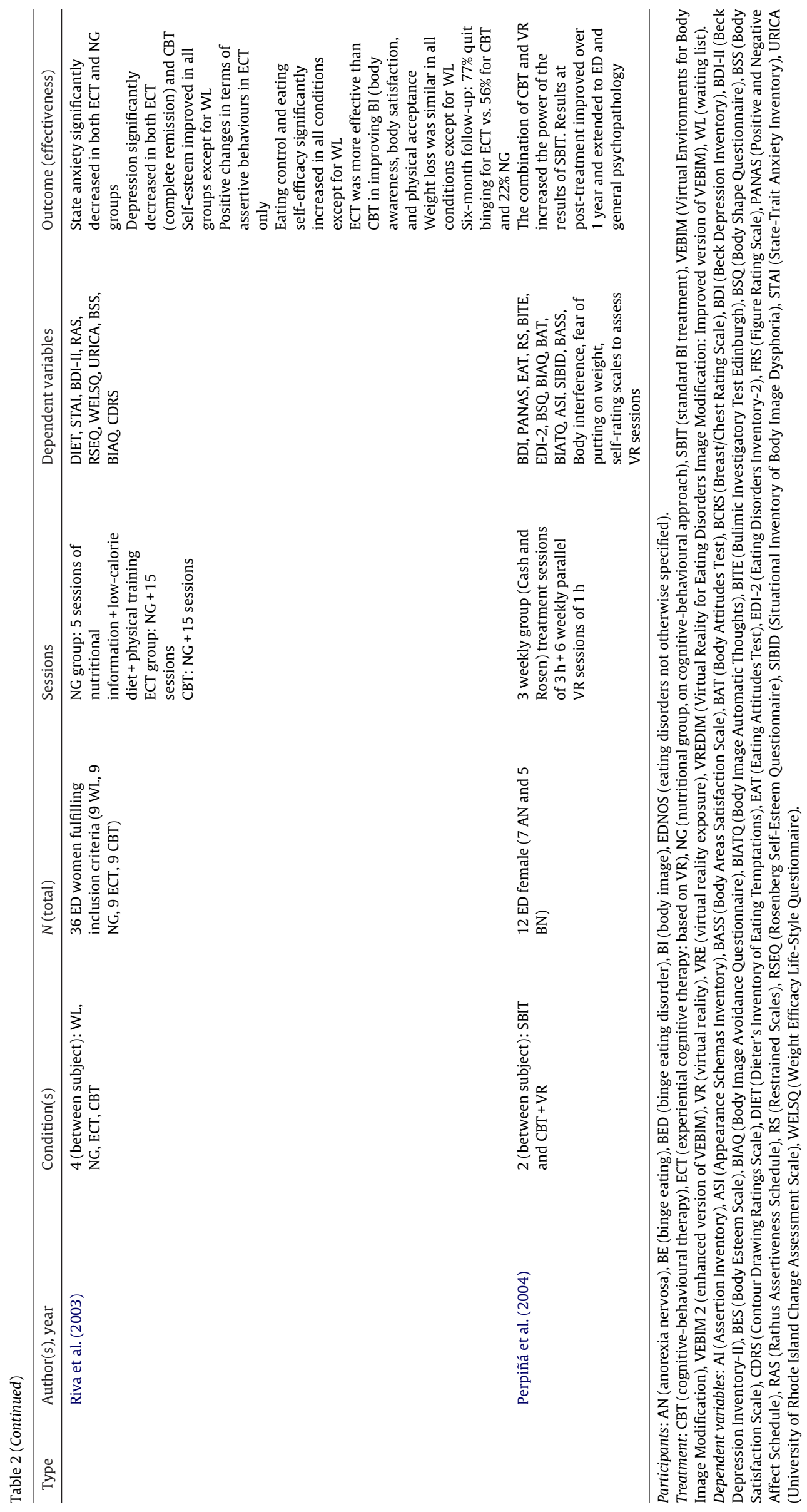


assigned to the waiting-list group (WL), the nutritional group (NG), the experiential cognitive therapy (ECT) group, and or cognitivebehavioural therapy (CBT) group. Participants were assessed before and after treatment. No differences were found between the WL condition and the treatment conditions at pre-treatment. There was a significant reduction of binge eating episodes in all the treatment groups. However, ECT was more effective than CBT and NG in improving body image (assessed with the BIAQ, BSS, and CDRS, see Table 2). Specifically, ECT patients scored significantly higher after the treatment on body awareness, body satisfaction, and physical acceptance. At 6-month follow-up, ECT group scored significantly better on body image than CBT and NG groups. Moreover, $77 \%$ of the ECT group still was not binging after 6 months versus 56\% for the CBT and $22 \%$ for the NG.

Several conclusions can be drawn from reviewed studies. VRbased therapies seem to be especially suitable for improving body image both in ED patients and in subclinical samples. Table 2 includes four controlled studies conducted with clinical samples that compare VR-based interventions with other therapies such as CBT and NG. All these studies showed significantly greater improvement in measures related with body image when the VR component was added. Moreover, data suggest that found improvements are even greater at follow-up. Therefore, VR-based treatment seems to be superior to receiving no treatment, and at least as effective as most used interventions. Furthermore, only one study reported two cases of simulator sickness (Riva, 1998c). These data are relevant because women are especially susceptible to such disturbances (Griffin, 1990). Thus, findings support the possibility of using VR for therapeutic purposes without fear of unpleasant side effects. However, several methodological drawbacks should be also considered to assess reviewed studies: first, few controlled studies have been conducted (only four with clinical samples); second, most studies used small samples; finally, few studies report followup results. Given these methodological drawbacks, our conclusions should be tentative. Consequently, although examined results suggest that VR-based therapy is an effective intervention for treating body image disturbances, more controlled studies with larger clinical samples are needed. It is worth noting that further studies on the use of virtual reality in the treatment of body image disturbances are required beyond the work of the two primary abovementioned research groups.

\section{Summary and Conclusions}

Anorexia and bulimia nervosa are now among the most severe mental disorders in adolescents and young adults. Both clinical experience and research have shown that body image disturbances play an important role in the onset, course, and prognosis of these pathologies, and the two main classificatory systems of mental disorders (DSM-IV and ICD-10) include the presence of a body image disturbance as a necessary criterion for their diagnosis. However, despite the large body of research on body image disturbances in eating disorders the concept itself is not easy to address. Virtual reality technology offers a new resource to study, assess, and treat these disturbances, contributing to increased knowledge and clinical management of body image disturbances.

The groups of Riva (e.g., Riva et al., 2002, 2003; Riva \& Melis, 1997) and Perpiñá (e.g., Perpiñá et al., 1999, 2003, 2004) have each developed different virtual environments for the assessment and treatment of body image disturbances in ED patients and nonclinical samples. These authors suggest that the addition or combination of virtual reality to other treatments, such as visualmotor and cognitive-behavioural therapy, improves body image dissatisfaction. Virtual reality seems also useful for conducting experimental studies into the nature of body image disturbances in eating disorders. The research group of Gutiérrez-Maldonado, for example, began by showing the ability of virtual environments to trigger real-life-like emotional responses in patients with eating disorders and controls (Ferrer-García et al., 2009; GutiérrezMaldonado et al., 2006), and then successfully used them to study body image as a state (Gutiérrez-Maldonado et al., 2010).

Nevertheless, this review also highlights the need of further research and the use of stronger methods in this field. As Gregg and Tarrier claimed (2007), more controlled studies comparing VR-based therapies and other treatments are needed, using larger samples and providing information about effect sizes. Virtual reality is potentially a useful technology for the assessment and treatment of body image disturbances in eating disorders, as well as a powerful resource for furthering our knowledge about these pathologies. The main advantages of this technology are its ability to represent a concept as subjective as body image, and to provide patients with solid and therapist-independent information about the erroneous mental representation of their body image. Hence, we strongly encourage researchers to continue studies on the use of VR in the study, assessment, and treatment of ED.

Although previous reviews about virtual reality and ED have been published (e.g., Myers, Swan-Kreimer, Wonderlich, Lancaster, \& Mitchell, 2004; Perpiñá et al., 2003; Riva \& Molinari, 2009), the present review is, to the best of our knowledge, the most complete review of the use of VR that focuses on body image. Future research should focus: first, on conducting more controlled studies comparing VR-based treatments with traditional ones; and, secondly, on using meta-analysis techniques in order to test the real strength of effects found in the reviewed studies.

\section{Acknowledgments}

This study was supported by the Spanish Ministry of Education and Science (Consolider Project SEJ2006-14301/PSIC: "New information and communication technologies: integration and consolidation of their use in social sciences to improve health, quality of life and well-being"; and the Research Project SEJ200509170-C04-01) and by a scholarship from La Caixa ("Obra Social”) granted to the first author.

\section{References}

Aimé, A., Cotton, K., \& Bouchard, S. (2009). Reactivity to virtual reality immersions in a subclinical sample of women concerned with their weight and shape. Journal of Cybertherapy and Rehabilitation, 2, 111-120.

American Psychiatric Association. (2000). Diagnostic and statistical manual for mental disorders (DSM IV-TR). Washington, DC: APA.

Baars, B. (1988). A cognitive theory of consciousness. New York: Cambridge University Press.

Botella, C., Baños, R., García-Palacios, A., Quero, S., Guillén, V., \& José-Marco, H. (2007). La utilización de las nuevas tecnologías de la información y la comunicación en psicología clínica. UOCPAPERS, 4, 32-41.

Botella, C., Baños, R., Perpiñá, C., \& Ballester, R. (1998). Realidad virtual y tratamientos psicológicos. Análisis y Modificación de Conducta, 24, 5-26.

Botella, C., Quero, S., Baños, R., Perpiñá, C., García-Palacios, A., \& Riva, G. (2004) Virtual reality and psychotherapy. In G. Riva, C. Botella, P. Legeron \& G. Optale (Eds.), Cybertherapy, internet and virtual reality as assessment and rehabilitation tools for clinical psychology and neuroscience (pp. 37-54). Amsterdam: IOS Press. Bruchon-Schweitzer, M. (1992). Psicología del cuerpo. Barcelona: Herder.

Carter, F., \& Bulik, C. M. (1994). Exposure treatments for bulimia nervosa: Procedure, efficacy, and mechanisms. Advances in Behavior Research and Therapy, 16, 77-129.

Casali, J. G. (1986). Vehicular simulation-induced sickness, Volume 1: An overview. IEOR Technical Report No. X501 (NTSC TR X6-010). Orlando, FL: Naval Training Systems Center.

Cash, T. F. (1990). The psychology of physical appearance: Aesthetics, attributes and images. In T. F. Cash \& T. Pruzinsky (Eds.), Body images: Development, deviance, and change (pp. 51-79). New York: Guilford Press.

Cash, T. F. (1996). The treatment of body image disturbances. In J. K. Thompson (Ed.), Body image, eating disorders, and obesity (pp. 83-107). Washington, DC: APA.

Cash, T. F., \& Brown, T. A. (1987). Body image in anorexia nervosa and bulimia nervosa: A review of the literature. Behavior Modification, 11, 487-521. 
Cash, T. F., \& Deagle, E. A. (1997). The nature and extend of body image disturbances in anorexia nervosa and bulimia nervosa: A meta-analysis. International Journal of Eating Disorders, 22, 107-125.

Cash, T. F., Fleming, E. C., Alindogan, J., Steadman, L., \& Whitehead, A. (2002) Beyond body image as a trait: The development and validation of the Body Image States Scale. Eating Disorders: The Journal of Treatment \& Prevention, 10 , $103-113$.

Côté, S., \& Bouchard, S. (2008). Virtual reality exposure's efficacy in the treatment of specific phobias: A critical review. Journal of Cybertherapy and Rehabilitation, 1 , 75-91.

Crisp, A. H., \& Kalucy, R. S. (1974). Aspects of the perceptual disorder in anorexia nervosa. British Journal of Medical Psychology, 47, 349-361.

Cukor, J., Spitalnick, J., Difede, J. A., Rizzo, A., \& Rothbaum, B. O. (2009). Emerging treatments for PTSD. Clinical Psychology Review, 28, 715-726.

Ebenholtz, S. M. (1992). Motion sickness and oculomotor systems in virtual environments. Presence, 1, 302-305.

Etu, S. F., \& Gray, J. J. (2010). A preliminary investigation of the relationship between induced rumination and state body image dissatisfaction and anxiety. Body Image, 7, 82-85.

Ferrer-García, M., \& Gutiérrez-Maldonado, J. (2008). Body Image Assessment Software: Psychometric data. Behavior Research Methods, 40, 394-407.

Ferrer-García, M., \& Gutiérrez-Maldonado, J. (2010). Effect of mood produced by virtual reality exposure on body image disturbances. Studies in Health Technology and Informatics, 154, 44-49.

Ferrer-García, M., Gutiérrez-Maldonado, J., Caqueo-Urízar, A., \& Moreno, E. (2009). The validity of virtual environments for eliciting emotional responses in patients with eating disorders and in controls. Behavior Modification, 3 , 830-854.

Freeman, R. J., Beach, B., Davis, R., \& Solyom, R. (1985). The prediction of relapse in bulimia nervosa. Journal of Psychiatric Research, 19, 349-353.

Gardner, R. M. (2002). Assessment of body image disturbance in children and adolescents. In J. K. Thompson \& L. Smolak (Eds.), Body image, eating disorders and obesity in youth (pp. 193-213). Washington, DC: APA

Glantz, K., Rizzo, A., \& Graap, K. (2003). Virtual reality for psychotherapy: Curren reality and future possibilities. Psychotherapy, 40, 55-67.

Gleaves, D. H., \& Eberenz, K. (1993). The psychopathology of anorexia nervosa: A factor analytic investigation. Journal of Psychopathology and Behavioral Assessment, $15,141-152$.

Gorini, A., Griez, E., Petrova, A., \& Riva, G. (2010, July). Assessment of emotional responses produced to real food, virtual food and photographs of food in patients affected by eating disorders. Annals of General Psychiatry, 9. Retrieved from. http://www.annals-general-psychiatry.com/content/9/1/30

Gorini, A., \& Riva, G. (2008). Virtual reality in anxiety disorders: The past and the future. Expert Reviews Neurotherapeutics, 8, 1-19.

Gregg, L., \& Tarrier, N. (2007). Virtual reality in mental health: A review of the literature. Social Psychiatry and Psychiatric Epidemiology, 42, 343-354.

Griffin, M. J. (1990). Handbook of human vibration. London: Academic Press.

Gutiérrez-Maldonado, J. (2009). Presentación. Anuario de Psicología, 40, 149-154

Gutiérrez-Maldonado, J., Ferrer-García, M., Caqueo-Urízar, A., \& Letosa-Porta, A (2006). Assessment of emotional reactivity produced by exposure to virtual environments in patients with eating disorders. CyberPsychology \& Behavior, 9 , 507-513.

Gutiérrez-Maldonado, J., Ferrer-García, M., Caqueo-Urízar, A., \& Moreno, E. (2010). Body image in eating disorders: The influence of exposure to virtual environments. CyberPsychology \& Behavior, 13, 521-531.

Haimovitz, D., Lansky, L. M., \& O'Reilly, P. (1993). Fluctuations in body satisfaction across situations. International Journal of Eating Disorders, 13, 77-84

Heilbrun, A. B., \& Flodin, A. (1989). Food cues and perceptual distortion of the female body: Implications for food avoidance in the early dynamics of anorexia nervosa. Journal of Clinical Psychology, 45, 843-851.

Krijn, M., Emmelkamp, P. M. G., Olafson, R. P., \& Biemond, R. (2004). Virtual reality exposure therapy of anxiety disorders: A review. Clinical Psychology Review, 24 259-281.

Laberg, J. C., Wilson, G. T., Eldredge, K., \& Nordby, H. (1991). Effects of mood on heart rate reactivity in bulimia nervosa. International Journal of Eating Disorders, 10 169-178.

Lattimore, P., \& Hutchinson, R. (2010). Perceived calorie intake and state body-image satisfaction in women attempting weight loss: A preliminary investigation. Body Image, 7, 15-21.

Maher, N. E., \& Gold, J. I. (2009). The use of virtual reality for pain control: A review. Current Pain and Headache Reports, 13, 100-109.

McKenzie, S. J., Williamson, D. A., \& Cubic, B. A. (1993). Stable and reactive body image disturbance in bulimia nervosa. Behavior Therapy, 24, 195-207.

Meyerbröker, K., \& Emmelkamp, P. M. G. (2010). Virtual reality exposure therapy in anxiety disorders: A systematic review of process- and outcome studies. Depression and Anxiety, 27, 933-944.

Myers, P. N, \& Biocca, F. A. (1992). The elastic body image: The effect of television advertisement and programming on body image distortions in young women. Journal of Communication, 42, 108-133.

Myers, T. C., Swan-Kreimer, L., Wonderlich, S., Lancaster, K., \& Mitchell, J. E. (2004) The use of alternative delivery systems and new technologies in the treatment of patients with eating disorders. International Journal of Eating Disorders, 36 , 123-143.

Norcross, J. C., Hedges, M., \& Prochaska, J. O. (2002). The face of 2010: A Delphi poll on the future of psychotherapy. Professional Psychology: Research \& Practice, 33 316-322.
Parsons, T. D., \& Rizzo, A. A. (2008). Affective outcomes of virtual reality exposure therapy for anxiety and specific phobias: A meta-analysis. Journal of Behavior Therapy and Experimental Psychiatry, 39, 250-261.

Pérez, B., Gutiérrez, J., \& Ferrer, M. (2004, April). Cuestionario de Depresión Barcelona: evaluación del curso de la depresión. In VII European Conference on Psychological Assessment Málaga (Spain).

Perpiñá, C., Baños, R., Botella, C., \& Marco, J. H. (2001). Virtual reality as a therapy tool: A case study on body image alteration disorders. Revista Argentina de Clínica Psicológica, 10, 227-241.

Perpiñá, C., Botella, C., \& Baños, R. M. (2000). Imagen Corporal en los Trastornos Alimentarios. Evaluación y Tratamiento Mediante Realidad Virtual. Valencia: Promolibro.

Perpiñá, C., Botella, C., \& Baños, R. M. (2003). Virtual reality in eating disorders. European Eating Disorders Review, 11, 261-278.

Perpiñá, C., Botella, C., Baños, R. M., Marco, H., Alcañiz, M., \& Quero, S. (1999). Body image and virtual reality in eating disorders: Is exposure to virtual reality more effective than the classical body image treatment? CyberPsychology \& Behavior, 2, 149-159.

Perpiñá, C., Botella, C., Quero, S., Marco, J. H., \& Baños, R. M. (2001). Presentation at the VII European Council on Eating Disorders, ECED, 2001, Barcelona, Spain, September 2001. In Perpiñá, C., Botella C., \& Baños R. M. (2003). Virtual reality in eating disorders. European Eating Disorders Review, 11, 261-278.

Perpiñá, C., Marco, J. H., Botella, C., \& Baños, R. (2004). Tratamiento de la imagen corporal en los trastornos alimentarios mediante tratamiento cognitivo-comportamental apoyado con realidad virtual: Resultados al año de seguimiento. Psicología Conductual: Revista Internacional de Psicología Clínica y de la Salud, 12, 519-537.

Powers, M. B., \& Emmelkamp, P. M. G. (2008). Virtual reality exposure therapy for anxiety disorders: A meta-analysis. Journal of Anxiety Disorders, 22, 561-569.

Pruzinsky, T., \& Cash, T. F. (2002). Understanding body images. In T. F. Cash \& T. Pruzinsky (Eds.), Body image: A handbook of theory, research, and clinical practice (pp. 3-12). New York: Guilford Press.

Riva, G. (1998a). Virtual reality in psychological assessment: The Body Image Virtual Reality Scale. Cyber Psychology and Behavior, 1, 37-44.

Riva, G. (1998b). Modifications of body-image induced by virtual reality. Perceptual and Motor Skills, 86, 163-170.

Riva, G. (1998c). Virtual Environment for Body Image Modification: Virtual reality system for treatment of body image disturbances. Computers in Human Behavior, $14,477-490$.

Riva, G. (1998d). Virtual reality vs. virtual body: The use of virtual environments in the treatment of body image experience disturbances. CyberPsychology $\mathcal{\sigma}$ Behavior, 1, 129-138.

Riva, G. (2003). Virtual environments in clinical psychology. Psychotherapy: Theory, Research, Practice and Training, 40, 68-76.

Riva, G. (2005). Virtual reality in psychotherapy: Review. CyberPsychology \& Behavior, 8, 220-230.

Riva, G., Bacchetta, M., Baruffi, M., Defrance, C., Gatti, F., Galimberti, C., et al. (1999). VREPAR 2: VR in eating disorders. CyberPsychology \& Behavior, 2, 77-79.

Riva, G., Bachetta, M., Baruffi, M., \& Molinari, E. (2002). Virtual-reality-based multidimensional therapy for the treatment of body image disturbances in binge eating disorders: A preliminary controlled study. IEEE Transactions on Information Technology in Biomedicine: A Publication of the IEEE Engineering in Medicine and Biology Society, 6, 224-234.

Riva, G., Bacchetta, M., Baruffi, M., Rinaldi, S., \& Molinari, E. (1998). Experiential cognitive therapy in anorexia nervosa. Eating and Weight Disorders, 3, $141-150$.

Riva, G., Bacchetta, M., Baruffi, M., Rinaldi, S., \& Molinari, E. (1999). Virtual reality based experiential cognitive treatment of anorexia nervosa. Journal of Behavior Therapy and Experimental Psychiatry, 30, 221-230.

Riva, G., Bacchetta, M., Baruffi, M., Rinaldi, S., Vincelli, F., \& Molinari, E. (2000). Realtà virtual e trattamento dei disturbi del comportamento alimentare. Psicoterapia Cognitiva e Comportamentale, 6, 173-184.

Riva, G., Bacchetta, M., Cesa, G., Conti, S., \& Molinari, E. (2003). Six-month follow-up of in-patient experiential-cognitive therapy for binge eating disorders. CyberPsychology \& Behavior, 6, 251-258

Riva, G., \& Melis. (1997). Virtual reality for the treatment of body image disturbances. Studies in Health Technology and Informatics, 44, 95-111.

Riva, G., Melis, L., \& Bolzoni, M. (1997). Treating body image disturbances. Communications of the ACM, 40,69-71.

Riva, G., \& Molinari, E. (2009). Virtual reality in eating disorders and obesity. CyberTherapy \& Rehabilitation, 2, 16-19.

Rorty, M., Yager, J., \& Rossotto, E. (1993). Why and how do women recover from bulimia nervosa? The subjective appraisals of forty women recovered for a year or more. International Journal of Eating Disorders, 14, 249-260.

Rosen, J. C. (1996). Body image assessment and treatment in controlled studies of eating disorders. International Journal of Eating Disorders, 20, 331-343.

Rosen, J. C. (1997). Cognitive-behavioural body image therapy. In D. M. Garner \& P. E. Garfinkel (Eds.), Handbook of treatment for eating disorders (pp. 188-201). New York: Guilford Press.

Rosen, J. C., \& Ramírez, E. (1998). A comparison of eating disorders and body dysmorphic disorder on body image and psychological adjustment. Journal of Psychosomatic Research, 44, 441-449.

Rudiger, J. A., Cash, T. A., Roehrig, M., \& Thompson, J. K. (2007). Day-to-day bodystates: Prospective predictors of intra-individual level of variability. Body Image, $4,1-9$.

Salorio, P., Gómez, R., Morales, I., Torres, A., Díaz, A., \& Alegría, A. (2004, November) La realidad virtual, una nueva herramienta terapéutica. Tratamiento de la 
imagen corporal en los trastornos alimentarios. Revista Electrónica Semestral de Enfermería, 5, 1-17. Retrieved from. http://revistas.um.es/eglobal/article/ view/543/563

Schilder, P. F. (1935). Image and appearance of the human body. Londres: Kegan Paul, Trench Trubner and Co.

Slade, P. D. (1988). Body image in anorexia nervosa. British Journal of Psychiatry, 153, 20-22.

Slade, P. D., \& Brodie, D. (1994). Body image distortion and eating disorder: A reconceptualization based on recent literature. European Eating Disorders Review, 1, $32-46$.

Slade, P. D., \& Russell, G. F. (1973). Awareness of body dimensions in anorexia nervosa: Cross-sectional and longitudinal studies. Psychological Medicine, 3, 188-199.

Smeets, M. A. M. (1997). The rise and fall of body size estimation research in anorexia nervosa: A review and reconceptualization. European Eating Disorders Review, 5, 75-95.

Spielberger, C. D., Gorsuch, R. L., \& Lushene, R. E. (1970). Handbook of STAI. Palo Alto, CA: Consulting Psychologist Press. (Spanish adaptation: Seisdedos, N. (1988). Barcelona: Ediciones TEA).

Striegel-Moore, R. H., \& Cachelin, F. M. (2001). Etiology of eating disorders in women. The Counseling Psychologist, 29, 635-661.
Striegel-Moore, R. H., Franko, D. L., Thompson, D., Barton, B., Schreiber, G. B., \& Daniels, S. R. (2004). Changes in weight and body image over time in women with eating disorders. International Journal of Eating Disorders, 36, 315-327.

Thompson, J. K. (1990). Body image disturbance: Assessment and treatment. New York: Pergamon.

Thompson, J. K. (Ed.). (1996). Body image, eating disorders, and obesity. Washington, DC: American Psychological Association.

Thompson, J. K., Heinberg, L. J., Altabe, M., \& Tantleff-Dunn, S. (1999). Exacting beauty: Theory, assessment and treatment of body image disturbance. Washington, DC: American Psychological Association.

Vanardo, P.J., Williamson, D. A., \& Netemeyer, R. (1995). Confirmatory factor analysis of eating disorders symptoms in college women. Journal of Psychopathology and Behavioral Assessment, 17, 68-78.

Wardle, J., \& Foley, E. (1989). Body image: Stability and sensitivity of body satisfaction and body size estimation. International Journal of Eating Disorders, 8 , 55-62.

Williamson, D. A., Davis, C. J., Bennett, S. M., Goreczny, A. J., \& Gleaves, D. H. (1989). Development of a simple procedure for assessing body image disturbance. Behavioral Assessment, 11, 433-446.

Zimmerman, T. G., Lanier, J., Blanchard, C., Bryson, S., \& Harvill, Y. (1986). A hand gesture interface device. ACM SIGCHI Bulletin, 189-192. 